Centre interuniversitaire de recherche

en économie quantitative

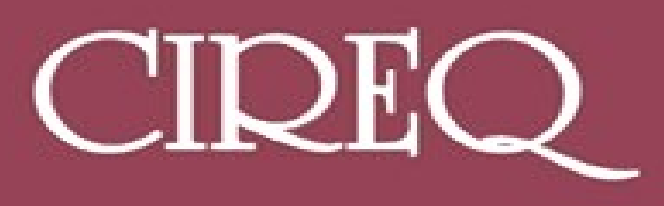

Cahier 12-2010

Free Trade, Autarky and the Sustainability of an International Environmental Agreement

Hassan BENCHEKROUN and Halis Murat YILDIZ 


\title{
CIREQ
}

Le Centre interuniversitaire de recherche en économie quantitative (CIREQ) regroupe des chercheurs dans les domaines de l'économétrie, la théorie de la décision, la macroéconomie et les marchés financiers, la microéconomie appliquée et l'économie expérimentale ainsi que l'économie de l'environnement et des ressources naturelles. Ils proviennent principalement des universités de Montréal, McGill et Concordia. Le CIREQ offre un milieu dynamique de recherche en économie quantitative grâce au grand nombre d'activités qu'il organise (séminaires, ateliers, colloques) et de collaborateurs qu'il reçoit chaque année.

The Center for Interuniversity Research in Quantitative Economics (CIREQ) regroups researchers in the fields of econometrics, decision theory, macroeconomics and financial markets, applied microeconomics and experimental economics, and environmental and natural resources economics. They come mainly from the Université de Montréal, McGill University and Concordia University. CIREQ offers a dynamic environment of research in quantitative economics thanks to the large number of activities that it organizes (seminars, workshops, conferences) and to the visitors it receives every year.

\section{Cahier 12-2010}

\section{Free Trade, Autarky and the Sustainability of an International Environmental Agreement}

\author{
Hassan BENCHEKROUN and Halis Murat YILDIZ
}

CIREQ, Université de Montréal C.P. 6128, succursale Centre-ville Montréal (Québec) H3C 3J7 Canada cireq@umontreal.ca http://www.cireq.umontreal.ca
Universite th de Montréal 
Dépôt légal - Bibliothèque nationale du Canada, 2010, ISSN 0821-4441

Dépôt légal - Bibliothèque et Archives nationales du Québec, 2010 ISBN-13 : 978-2-89382-600-4 


\title{
Free Trade, Autarky and the Sustainability of an International Environmental Agreement
}

\author{
Hassan Benchekroun ${ }^{\ddagger *}$ and Halis Murat Yildiz ${ }^{\dagger}$ \\ ${ }^{\ddagger}$ Department of Economics, McGill University and CIREQ, Montreal, Canada \\ ${ }^{\dagger}$ Department of Economics, Ryerson University, Toronto, Canada
}

September 6, 2009

\begin{abstract}
We determine the impact of free trade on the sustainability of an international environmental agreement (IEA) and incorporate it into the assessment of the net benefits of opening up to free trade. We show that such an analysis can reverse the conclusions reached within a standard oneshot game framework. First, we examine a one shot game and argue that the benefits from an increase in economic activity due to free trade outweigh the extra cost of free trade associated with larger environmental damage. Then, we analyze the infinite repetition of the one-shot game where countries can use trigger strategies and show that there exist circumstances where an IEA is sustainable under autarky but not under free trade. This aggravates the environmental damages caused by free trade and leads to the possibility that autarky may welfare dominate free trade. This conclusion remains valid even when countries adopt the most cooperative environmental policy when the "fully cooperative" environmental policy is not sustainable.
\end{abstract}

JEL Classifications: F12, Q56

\footnotetext{
*Corresponding author: Phone: (514) 398-8965; Fax: (514) 398-4849; c-mail: hassan.benchekroun@mcgill.ca.
} 


\section{Introduction}

As the world economy has become increasingly integrated, there has been a growing concern over the effects of international trade on the global environment. Environmentalists have generally considered international economic integration as a threat to adequate environmental regulation. It is often argued that freer trade cause more environmental degradation via an increase in consumption and production. Therefore, even if opening up to trade succeeds in raising income and consumption levels, it only leads to more pollution. As global economic integration intensifies, the potential for conflict becomes more transparent (see Lawrence et al., 1996; Dua and Esty, 1997). Maybe, the best summary on the linkage between environment and trade is articulated by Bhagwati (1993):

“...The environmentalists' antipathy to trade is perhaps inevitable. Trade has been central to economic thinking since Adam Smith discovered the virtues of specialization and of the markets that naturally sustain it. Because markets do not normally exist for the pursuit of environmental protection, they must be specially created. Trade therefore suggests abstention from governmental intervention, whereas environmentalism suggests its necessity."

Since the early 1990s, the connection between trade and environment has become a dominant international policy issue. ${ }^{1}$ One of the main questions in the literature has been about the strategic distortions that trade introduces in designing environmental policies and the effects that trade liberalization has on these distortions (see Kennedy, 1994; Barrett,1994b; Ulph, 1996a and 1996b; Burguet, 2003; Straume, 2006 and Baksi and Chaudhuri, 2008). It is argued that trade-related incentives tend to reduce environmental protection, although the distortions are likely to decrease as trade gets liberalized.

Many environmental problems - including global warming (climate change), marine pollution, ozone layer depletion and biodiversity loss - are transboundary and thus cannot effectively be dealt with by any country alone. In such cases, while collective well-being can be increased with full cooperation in managing shared environmental resources, we know form the existing literature that two main factors severely limit the effectiveness of environmental agreements. ${ }^{2}$ First, the gains from environmental cooperation are typically examined through a comparison between a situation of complete non-cooperation and a situation of complete cooperation. However, a country would prefer a situation in which it behaves non-cooperatively while the other countries cooperate amongst themselves (thus allowing the non-cooperating country to free-ride on the improved environment). The second obstacle is the lack of a supranational authority with well defined and effective enforcement powers. Based upon these observations, we follow an influential stream of the literature, see e.g. Barrett (1994a), Finus (2001), Rubio and Ulph (2002), and Ferrara et. al (2009), and focus on IEAs within an infinitely repeated game where an agreement is self sustainable through the use of

\footnotetext{
${ }^{1}$ The Special Stuidies on Trade and Environment by WTO (1999) argue that economic integration has important environmental repurcussions.

${ }^{2}$ See Carraro and Siniscalco (1993), Barrett (1994a), Finus (2001) and Rubio and Ulph (2002), and Ferrara et. al (2009).
} 
trigger strategies. This approach seems the most appropriate since IEAs have to be self-enforcing in the sense that they are immune to unilateral deviations by the countries involved without requiring any external authority.

The objective of this paper is to evaluate the implications of opening up to free trade when the resulting increase in economic activity is accompanied by environmental damages. To this end, we employ a simple oligopoly model of trade between two countries where the pollution generated is a transboundary public bad that affects both countries equally, regardless of the point of origin. Our main contribution is to incorporate the sustainability of environmental cooperation in a repeated game into the welfare analysis of free trade versus autarky.

We first derive the subgame perfect Nash equilibrium of a two stage one-shot game under autarky and under free trade. In the first stage, countries choose - cooperatively or non cooperatively- their emission standards. In the second stage, taking the emission standards as given, firms compete a la Cournot in the product markets. In the one shot game, we find a result that provides a confirmation to the existing literature regarding the tension on the policy arena: free trade yields larger social welfare (measured as the sum of consumer surplus producer surplus net of the environmental damage) relative to autarky however this improvement in the 'standards of living' comes at the expense of the environmental quality. We also show that the losses from the absence of an IEA are aggravated under free trade relative to autarky.

We then analyze the infinite repetition of this one-shot game and determine whether an IEA is easier or harder to sustain under free trade than it is under autarky. Following the literature on trade and environmental agreements, we focus on self-enforcing agreements that are sustained by trigger strategies where countries cooperate until the deviation is observed in which case all countries revert back to the non-cooperative equilibrium. A country participates in a self-enforcing IEA when the benefit of deviating from the cooperative abatement standard is outweighed by the future losses it would suffer from the loss of cooperation. ${ }^{3}$ We first focus on the polar cases of cooperative and non-cooperative environmental policies. ${ }^{4}$ We find that while free trade raises both the environmental and welfare gains from an IEA relative to autarky, it makes an IEA less likely to be self-sustainable relative to autarky. This result implies that there exist circumstances where an IEA is sustainable under autarky but not under free trade. Under such a situation, free trade leads to an additional welfare cost that needs to be factored in the determination of the net social benefit from free trade relative to autarky. When the rate of increase in marginal cost of abatement is sufficiently large, we show that the environmental damage effect outweighs the pure trade effect and countries lose from free trade relative to autarky.

Finally, we check the robustness of the conclusions derived from these two limit cases (coopera-

\footnotetext{
${ }^{3}$ In the trade agreement literature, see Riezman (1991), Bagwell and Staiger (1997a), (1997b), and (1998), Bond et. al (2001) and Saggi (2006). In the environmental literature, see Carraro and Siniscalco (1993), Barrett (1994a), Finus (2001) and more recently Ferrara et. al (2009), Benchekroun and Yildiz (2009).

${ }^{4}$ In similar model, Benchekroun and Yildiz (2009) investigates the implications of trade liberalization on the sustainability of an IEA.
} 
tive environmental policies vs. non-cooperative environmental policies) by introducing the concept of the most cooperative environmental policy. Specifically, in the case where the discount rate is such that a fully cooperative environmental policy is not sustainable, we determine the most cooperative environmental policy that can still be sustainable. This approach is borrowed from the concept of most cooperative tariff in trade agreements (see Chisik, 2003 and Saggi, 2006). Our analysis provides a confirmation to the main result derived under the polar cases of cooperative and non-cooperative environmental policies: autarky can dominate free trade from a social welfare perspective.

\section{Basic Model}

Consider a simple oligopoly model of trade where there are two countries, $i$ and $j$, and two goods $x$ and $y$. For simplicity, we assume that the inverse demand for good $x$ in each country is linear:

$$
p_{i}\left(x_{i}\right)=\alpha-x_{i}
$$

where $p_{i}$ denotes the price and $x_{i}$ denotes the quantity of good $x$ sold in country $i$. Good $y$ is the numeraire good produced under perfect competition with constant returns to scale while good $x$ is produced by a single profit maximizing firm in each country. For simplicity, we refer to country $i$ 's firm as firm $i$ and marginal costs of production for both firms are assumed to be zero. Following Ulph (1996a), we assume that there is no pollution associated with the numeraire good while each unit of $x$ produced generates one unit of pollution emission and there exists a technology that allows for abatement. When country $i$ 's government imposes a cap on emissions via emission standards, denoted by $e_{i}$, abatement by firm $i$ is defined as follows:

$$
a_{i}=\operatorname{Max}\left(0, \sum_{z=i, j} x_{i z}-e_{i}\right) .
$$

where $x_{i z}$ denotes the sales of firm $i$ in country $z$.

The cost of achieving an abatement level $a_{i}$ is assumed to be convex:

$$
C_{i}\left(a_{i}\right)=\frac{\gamma a_{i}^{2}}{2}
$$

where $\gamma>0$ is the rate of increase in the marginal cost of abatement.

We assume that, as in Copeland and Taylor (1995), the pollution generated is a transboundary public bad that affects both countries equally, regardless of the point of origin. The level of pollution in country $i$ is given by $E_{i}=e_{i}+e_{j}$. The damage to country $i$, denote by $\Omega_{i}$, from a level of pollution $E_{i}$ is assumed to be convex:

$$
\Omega_{i}=\frac{E_{i}^{2}}{2}=\frac{\left(e_{i}+e_{j}\right)^{2}}{2}
$$

We first consider a two stage one shot game. In the first stage, countries choose - cooperatively or non cooperatively- their emission standards. In the second stage, taking the emission standards 
as given, firms compete in a Cournot fashion in the product markets. Using backward induction, we obtain a subgame perfect Nash equilibrium (SPNE).

\section{One-shot game}

Next, we analyze and compare the outcomes of the one shot game for two scenarios: autarky and free trade between countries $i$ and $j$.

\subsection{Autarky}

Consider first the autarky case in which there is no commodity trade between the two countries. Under autarky, firm $i$ takes the environmental policies $\left(e_{i}, e_{j}\right)$ as given and maximizes the following profit function:

$$
\max _{x_{i}} \pi_{i}=p_{i} x_{i}-\frac{\gamma}{2}\left(x_{i}-e_{i}\right)^{2}
$$

It is straightforward to determine the Cournot Nash equilibrium:

$$
x_{i i}=\frac{\alpha+\gamma e_{i}}{2+\gamma} \text { and } p_{i}=\frac{\alpha(1+\gamma)-\gamma e_{i}}{2+\gamma}
$$

In the first stage of the game, in the non-cooperative equilibrium, each country takes the environmental policy of the other country as given and determines its emission standard that maximizes its own welfare:

$$
\operatorname{Max}_{e_{i}} W_{i}\left(e_{i}, e_{j}\right)=\underbrace{\frac{\left(\alpha+\gamma e_{i}\right)^{2}}{2(2+\gamma)^{2}}}_{C S_{i}\left(e_{i}\right)}+\underbrace{\frac{\alpha^{2}+2 \gamma e_{i}\left(\alpha-e_{i}\right)}{2(2+\gamma)}}_{P S_{i}\left(e_{i}\right)}-\underbrace{\frac{\left(e_{i}+e_{j}\right)^{2}}{2}}_{\Omega_{i}\left(e_{i}, e_{j}\right)}
$$

$C S_{i}\left(e_{i}\right)=U\left(x_{i}\right)-p_{i} x_{i}$ denotes consumer surplus in country $i ; P S_{i}\left(e_{i}\right)=\pi_{i}$ denotes producer surplus; and $\Omega_{i}\left(e_{i}, e_{j}\right)$ is the environmental damage in country $i$. First order conditions (F.O.Cs) for the above problem imply that consumer surplus, producer surplus and environmental damage rise in $e_{i}$ :

$$
\frac{\partial W_{i}}{\partial e_{i}}=\underbrace{\frac{\gamma\left(\alpha+\gamma e_{i}\right)}{(2+\gamma)^{2}}}_{\frac{\partial C S_{i}\left(e_{i}\right)}{\partial e_{i}}>0}+\underbrace{\frac{\gamma\left(\alpha-2 e_{i}\right)}{2+\gamma}}_{\frac{\partial P S_{i}\left(e_{i}\right)}{\partial e_{i}}>0}-\underbrace{\left(e_{i}+e_{j}\right)}_{\frac{\partial \Omega_{i}\left(e_{i}, e_{j}\right)}{\partial e_{i}}>0}=0
$$

It is straightforward to argue that emission standards are strategic substitutes:

$$
\frac{\partial e_{i}}{\partial e_{j}}=-\frac{1}{\frac{\gamma(\gamma+4)}{(2+\gamma)^{2}}+1}<0
$$

Thus, each country has an incentive to relax its environmental policy if the rival country adopts a more stringent environmental policy. From the F.O.Cs above, we obtain the non-cooperative equilibrium emission standard, denoted by $e^{\phi-A}$ :

$$
e^{\phi-A}=\frac{\alpha \gamma(3+\gamma)}{2(2+\gamma)^{2}+\gamma(\gamma+4)}
$$


It is immediate to argue that as the rate of increase in the marginal cost of abatement $(\gamma)$ rises, each country has an incentive to follow less stringent environmental policy: $\frac{\partial e^{\phi-A}}{\partial \gamma}>0$.

Let $W\left(e^{\phi-A}\right)$ denote welfare of a country under autarky when there is no environmental cooperation:

$$
W\left(e^{\phi-A}\right)=W_{i}\left(e^{\phi-A}, e^{\phi-A}\right)=\frac{\alpha^{2}(3+\gamma)\left[\gamma^{2}(\gamma-4)+16(1+\gamma)^{2}\right]}{2\left[2(2+\gamma)^{2}+\gamma(\gamma+4)\right]^{2}} .
$$

Now, consider the scenario in which countries are engaged in an IEA whereby they determine their joint emission standards (denoted by $e^{c-A}$ ) by maximizing the sum of their welfare:

$$
\max _{e} W W(e)=\sum_{j} W_{j}(e, e)
$$

The F.O.C. for the above problem is

$$
\frac{\partial W W}{\partial e}=\frac{2 \gamma(\alpha+\gamma e)}{(2+\gamma)^{2}}+\frac{2 \gamma(\alpha-2 e)}{2+\gamma}-8 e=0
$$

Using (13), $e^{c}$ is given by:

$$
e^{c-A}=\frac{\alpha \gamma(3+\gamma)}{4(2+\gamma)^{2}+\gamma(\gamma+4)}
$$

It is immediate from (10) and (14) that, since an IEA internalizes the negative externality, environmental standards are more stringent under an IEA relative to no agreement and more so as $\gamma$ rises:

$$
\Delta e^{A}=e^{\phi-A}-e^{c-A}=\frac{2 \alpha \gamma(3+\gamma)(2+\gamma)^{2}}{\left[4(2+\gamma)^{2}+\gamma(\gamma+4)\right]\left[2(2+\gamma)^{2}+\gamma(\gamma+4)\right]}>0
$$

where $\frac{\partial \Delta e^{A}}{\partial \gamma}>0$. Let $W\left(e^{c-A}\right)$ denote the welfare of a country under autarky when there exists an IEA:

$$
W\left(e^{c-A}\right)=\frac{\alpha^{2}(3+\gamma)(\gamma+4)}{2\left[4(2+\gamma)^{2}+\gamma(\gamma+4)\right]}
$$

\subsection{Free Trade}

Now suppose that countries open up to trade and there exist no trade costs or barriers. Firm $i$ maximizes the following profit function

$$
\max _{x_{i z}} \pi_{i}=\sum_{z=i, j} p_{z} x_{i z}-\frac{\gamma}{2}\left(\sum_{z=i, j} x_{i z}-e_{i}\right)^{2}
$$

It is straightforward to determine the Cournot Nash equilibrium:

$$
x_{i i}=x_{i j}=\frac{\alpha(1+2 \gamma)+\gamma\left[2 e_{i}(1+\gamma)-e_{j}\right]}{(2 \gamma+3)(1+2 \gamma)} \text { and } p_{i}=\frac{\alpha(1+2 \gamma)-\gamma\left[e_{i}+e_{j}\right]}{(2 \gamma+3)}
$$

In the first stage, countries simultaneously determine their emission standards under no cooperation:

$$
\underset{e_{i}}{\operatorname{Max}} W_{i}\left(e_{i}, e_{j}\right) \equiv C S_{i}\left(e_{i}, e_{j}\right)+P S_{i}\left(e_{i}, e_{j}\right)-\Omega_{i}\left(e_{i}, e_{j}\right)
$$


The first order condition for the above problem is given by

$$
\frac{\partial W_{i}}{\partial e_{i}}=\frac{2 \gamma \alpha\left(4 \gamma^{2}+10 \gamma+5\right)}{(1+2 \gamma)(2 \gamma+3)^{2}}-e_{i}\left[\frac{\gamma\left(12 \gamma^{3}+36 \gamma^{2}+31 \gamma+9\right)}{(1+2 \gamma)^{2}(2 \gamma+3)^{2}}+1\right]-e_{j}\left[\frac{\gamma^{2}\left(4 \gamma^{2}+12 \gamma+7\right)}{(1+2 \gamma)^{2}(2 \gamma+3)^{2}}+1\right]=0
$$

Similar to autarky, $e_{i}$ and $e_{j}$ are strategic substitutes:

$$
\frac{\partial e_{i}}{\partial e_{j}}=-\frac{\frac{\gamma^{2}\left(4 \gamma^{2}+12 \gamma+7\right)}{(1+2 \gamma)^{2}(2 \gamma+3)^{2}}+1}{\frac{\gamma\left(12 \gamma^{3}+36 \gamma^{2}+31 \gamma+9\right)}{(1+2 \gamma)^{2}(2 \gamma+3)^{2}}+1}<0
$$

Thus, each country would relax its environmental policy if the rival country adopts a more stringent environmental policy. It is immediate from (9) and (21) that opening up to free trade increases the interdependency of environmental policy of countries and thus raises $\left|\frac{\partial e_{i}}{\partial e_{j}}\right|:\left|\frac{\partial e_{i}}{\partial e_{j}}\right|^{F}>\left|\frac{\partial e_{i}}{\partial e_{j}}\right|^{A}$. It is mainly due to the fact that profit shifting considerations arise under free trade while they do not exist under autarky.

Next, we obtain the non-cooperative equilibrium emission standard, denoted by $e^{\phi-F}$ :

$$
e^{\phi-F}=\frac{2 \gamma \alpha\left(5(\gamma+1)^{2}-\gamma^{2}\right)}{\gamma\left[9(\gamma+1)^{2}-\gamma^{2}+2 \gamma\right]+2(1+2 \gamma)(2 \gamma+3)^{2}}
$$

where $\frac{\partial e^{\phi-F}}{\partial \gamma}>0$ as under autarky.

Now consider an IEA under free trade where countries determine their joint standard:

$$
\frac{\partial W W}{\partial e}=\frac{8 \alpha \gamma(2+\gamma)}{(2 \gamma+3)^{2}}-e\left[\frac{2 \gamma(4 \gamma+9)}{(2 \gamma+3)^{2}}+8\right]=0
$$

and $e^{c-F}$ is given by:

$$
e^{c-F}=\frac{4 \alpha \gamma(2+\gamma)}{4(2 \gamma+3)^{2}+\gamma(4 \gamma+9)}
$$

As under autarky, relative to no agreement, an IEA leads to more stringent environmental standards under free trade:

$$
\Delta e^{F}=e^{\phi-F}-e^{c-F}=\frac{2 \alpha \gamma(2 \gamma+3)^{2}\left(8 \gamma^{2}+21 \gamma+12\right)}{\left[4(2 \gamma+3)^{2}+\gamma(4 \gamma+9)\right]\left[\gamma\left(8 \gamma^{2}+20 \gamma+9\right)+2(1+2 \gamma)(2 \gamma+3)^{2}\right]}>0
$$

Finally, let $W\left(e^{\phi-F}\right)$ and $W\left(e^{c-F}\right)$ denote the welfare of a country under free trade when there is no environmental cooperation and when there is an IEA, respectively. We have:

$$
\begin{gathered}
W\left(e^{\phi-F}\right)=\frac{2 \alpha^{2}(2+\gamma)(\gamma+4)}{4(2 \gamma+3)^{2}+\gamma(4 \gamma+9)}-\left[\Delta e^{F}\right]^{2}\left[\frac{4(2 \gamma+3)^{2}+\gamma(4 \gamma+9)}{2(2 \gamma+3)^{2}}\right] \\
W\left(e^{c-F}\right)=\frac{2 \alpha^{2}(2+\gamma)(\gamma+4)}{4(2 \gamma+3)^{2}+\gamma(4 \gamma+9)}
\end{gathered}
$$




\subsection{Free Trade versus Autarky: The one shot game}

In this section, we examine both social welfare and environmental implications of free trade relative to autarky under an IEA and no agreement. To this end, we first consider the scenario where the IEA does not exist. While the damage effect arises both under autarky and free trade, the profit shifting effect exists only under free trade. Thus, countries have incentives to follow less stringent environmental policy under free trade relative to autarky:

$$
e^{\phi-F}-e^{\phi-A}=\frac{\alpha \gamma(1+\gamma)(2+\gamma)(8 \gamma+13)}{\left[\gamma\left(9(\gamma+1)^{2}-\gamma^{2}+2 \gamma\right)+2(1+2 \gamma)(2 \gamma+3)^{2}\right]\left[2(2+\gamma)^{2}+\gamma(\gamma+4)\right]}>0
$$

Similarly, it is immediate from (14) and (24) that under an IEA countries follow less stringent environmental policy under free trade relative to autarky:

$$
e^{c-F}-e^{c-A}=\frac{\alpha \gamma(4+\gamma)(5+3 \gamma)}{\left[4(2 \gamma+3)^{2}+\gamma(4 \gamma+9)\right]\left[4(2+\gamma)^{2}+\gamma(\gamma+4)\right]}>0
$$

Next, under both autarky and free trade, we find the "environmental gain" from an IEA as the change of total environmental damage relative to no agreement:

$$
\Delta \Omega^{Z}=\Omega\left(e^{\phi-Z}\right)-\Omega\left(e^{c-Z}\right)=2 \Delta e^{Z}\left[e^{\phi-Z}+e^{c-Z}\right]>0, \text { where } Z=A, F
$$

In a similar way, we define the "welfare gain" from an IEA under each regime:

$$
\begin{gathered}
\Delta W^{A}=W^{c-A}-W^{\phi-A}=\left(\frac{\Delta e^{A}}{2}\right)^{2}\left[\frac{2 \gamma(\gamma+4)}{(2+\gamma)^{2}}+8\right]>0 \\
\Delta W^{F}=W\left(e^{c-F}\right)-W\left(e^{\phi-F}\right)=\left(\Delta e^{F}\right)^{2}\left[\frac{4(2 \gamma+3)^{2}+\gamma(4 \gamma+9)}{2(2 \gamma+3)^{2}}\right]>0
\end{gathered}
$$

The following result is immediate:

Proposition 1: Both social welfare and environmental gains from an IEA are larger under free trade relative to autarky: $\Delta W^{F}-\Delta W^{A}>0$ and $\Delta \Omega^{F}-\Delta \Omega^{A}>0$.

Consistent with the popular belief, the above proposition argues in favor of the idea that, both from welfare and environmental perspectives, there is more to gain from an IEA under free trade relative to autarky. This result can also interpreted as follows: free trade exacerbates the losses from the absence of an environmental agreements. Recently, it has been recognized that environmental impacts should be addressed in international trade agreements. ${ }^{5}$ However, although acknowledged, no specific solution to the problem of coordination over environmental policies is put forward. In what follows, we take into account the impact of opening up to free trade on the sustainability of an IEA, and then derive the welfare and environmental implications of free trade .

\footnotetext{
${ }^{5}$ See Barrett (1994b), Krugman (1997), Ederington (2001), Ederington and Minier (2003), Ederington (2009)
} 


\section{Sustaining environmental cooperation in a supergame}

In order to examine the self-sustainability of an IEA, we model the environmental cooperation as a stationary repeated game where cooperation can be sustained only if each country finds it profitable to do so. Specifically, we consider a supergame where the above one shot game is infinitely repeated. It is well-known that countries may sustain the cooperative equilibrium by using trigger strategies provided that the discount rate of future periods is sufficiently small. The trigger strategies typically prescribe adopting the cooperative solution unless a defection is observed. Defection by any country results in the permanent breakdown of cooperation in which case countries revert to the noncooperative equilibrium. In every period, each country weighs the current benefit of defecting from cooperation against the future cost of the breakdown of cooperation. If the current benefit of defection is less than the discounted life-time cost of defection for each country, no country has an incentive to deviate from the cooperative solution and thus cooperation is sustainable.

Since we examine whether an IEA is more likely to be sustainable under free trade than under autarky, we first determine the threshold levels of the discount factors under autarky and free trade, denoted by $\bar{\delta}^{A}$ and $\bar{\delta}^{F}$ respectively, beyond which an IEA is sustainable. We then compare these two critical discount factors.

To determine the benefit from defection under a regime $Z$ where $Z=A, F$, we first find the optimum emission standard of the defecting country (denoted by $e^{d-Z}$ ) while the other country uses the cooperative standard $\left(e^{c-Z}\right)$. Let

- $W_{i}\left(e^{c-Z}, e^{c-Z}\right)$ denote the per period welfare of country $i$ under an IEA in a regime $Z=A, F$;

- $W_{i}\left(e^{d-Z}, e^{c-Z}\right)$ denote the per period welfare of country $i$ when it defects from $e^{c-Z}$ and sets $e^{d-Z}$ given that country $j$ sets $e^{c-Z}$ in a regime $Z=A, F$ and

- $W_{i}\left(e^{\phi-Z}, e^{\phi-Z}\right)$ denote the per period welfare of country $i$ under no cooperation in a regime $Z=A, F$.

\subsection{Sustaining an IEA under Autarky}

We now determine the threshold level of the discount factor, denoted $\bar{\delta}^{A}$, beyond which an IEA is self-sustainable under autarky. Given the symmetric nature of our model, it is sufficient to consider country $i$ 's defection problem only:

$$
\max _{e_{i}} W_{i}\left(e_{i}, e^{c-A}\right)=C S_{i}\left(e_{i}, e^{c-A}\right)+P S_{i}\left(e_{i}, e^{c-A}\right)-\Omega_{i}\left(e_{i}, e^{c-A}\right) .
$$

The solution to the above problem is:

$$
e^{d-A}=\frac{2 \alpha \gamma(3+\gamma)^{2}(1+\gamma)}{[\gamma(\gamma+4)+2]\left[4(2+\gamma)^{2}+\gamma(\gamma+4)\right]}
$$

Note from (22), (14) and (33) that $e^{d-A} \geq e^{\phi-A} \geq e^{c-A}$ obtains. Given the above welfare definitions, country $i$ 's one-period benefit from defecting from $e^{c-A}$ to $e^{d-A}$ equals 


$$
\begin{aligned}
B_{i}\left(e^{d-A}, e^{c-A}\right) & =W_{i}\left(e^{d-A}, e^{c-A}\right)-W_{i}\left(e^{c-A}\right) \\
& =\frac{\left(e^{d-A}-e^{c-A}\right)^{2}\left(\frac{\gamma(\gamma+4)+(2+\gamma)^{2}}{(2+\gamma)^{2}}\right)}{2}>0 .
\end{aligned}
$$

As defection by any country results into a permanent breakdown of the agreement with each country reverting back to $e^{\phi-A}$, the one-period cost of defection equals to the difference between the one-period welfare under an IEA and the one-period welfare under no agreement:

$$
\begin{aligned}
C_{i}\left(e^{\phi-A}, e^{c-A}\right) & =W_{i}\left(e^{c-A}\right)-W_{i}\left(e^{\phi-A}\right) \\
& =\left(\frac{\Delta e^{A}}{2}\right)^{2}\left(\frac{2 \gamma(\gamma+4)}{(2+\gamma)^{2}}+8\right) \geq 0
\end{aligned}
$$

For cooperation to be sustainable, the current benefit of defection must be less than the discounted life-time cost of defection for each country. Thus, the incentive compatibility (IC) constraint must hold:

$$
B_{i}\left(e^{d-A}, e^{c-A}\right) \leq \frac{\delta}{1-\delta} C_{i}\left(e^{\phi-A}, e^{c-A}\right)
$$

where $\delta$ denotes the discount factor so that $\frac{\delta}{1-\delta} C_{i}\left(e^{\phi-A}, e^{c-A}\right)$ measures country $i$ 's permanent cost of defection. the critical discount factor $\bar{\delta}^{A}$ corresponds to the solution of $B_{i}\left(e^{d-A}, e^{c-A}\right)=$ $\frac{\delta}{1-\delta} C_{i}\left(e^{\phi-A}, e^{c-A}\right)$ :

$$
\bar{\delta}^{A}=\frac{\left[\gamma(\gamma+4)+2(2+\gamma)^{2}\right]^{2}}{\gamma(2+\gamma)^{2}(\gamma+4)+2\left[\gamma(\gamma+4)+2(2+\gamma)^{2}\right]^{2}} .
$$

Lemma 1: An IEA is self-sustainable under autarky if and only if $\delta \geq \bar{\delta}^{A}$ holds.

It is immediate from (37) that an IEA is more likely to be self-sustainable under autarky when the rate of increase in the marginal cost of abatement $(\gamma)$ rises: $\frac{\partial \bar{\delta}^{A}}{\partial \gamma}<0$. This is due to the fact that, as $\gamma$ increases, the cost of defection rises more than the benefit from defection: $\frac{\partial C_{i}\left(e^{\phi-A}, e^{c-A}\right)}{\partial \gamma}>\frac{\partial B_{i}\left(e^{d-A}, e^{c-A}\right)}{\partial \gamma}>0$.

\subsection{Sustaining an IEA under Free Trade}

We now determine the threshold level of the discount factor, denoted $\bar{\delta}^{F}$, beyond which an IEA is sustainable under free trade and compare it with $\bar{\delta}^{A}$. If $\bar{\delta}^{F}>\bar{\delta}^{A}\left(\bar{\delta}^{F}<\bar{\delta}^{A}\right)$ holds, we argue that an IEA is less (more) likely to be sustainable under free trade than under autarky. Under free trade, country $i$ 's defection problem is:

$$
\max _{e_{i}} W_{i}\left(e_{i}, e^{c-F}\right)=C S_{i}\left(e_{i}, e^{c-F}\right)+P S_{i}\left(e_{i}, e^{c-F}\right)-\Omega_{i}\left(e_{i}, e^{c-F}\right) .
$$

The solution to the above problem yields

$$
e^{d-F}=\frac{\left[\frac{2 \gamma \alpha\left(4 \gamma^{2}+10 \gamma+5\right)}{(1+2 \gamma)(2 \gamma+3)^{2}}-\left[\frac{\gamma^{2}\left(4 \gamma^{2}+12 \gamma+7\right)}{(1+2 \gamma)^{2}(2 \gamma+3)^{2}}+1\right]\left[\frac{4 \alpha \gamma(2+\gamma)}{4(2 \gamma+3)^{2}+\gamma(4 \gamma+9)}\right]\right]}{\left[\frac{\gamma\left(12 \gamma^{3}+36 \gamma^{2}+31 \gamma+9\right)}{(1+2 \gamma)^{2}(2 \gamma+3)^{2}}+1\right]} .
$$


As under autarky, it is immediate from (22), (24) and (39) that $e^{d-F} \geq e^{\phi-F} \geq e^{c-F}$. Given the above welfare definitions, country $i$ 's one-period benefit and cost of defection equal

$$
\begin{aligned}
B_{i}\left(e^{d-F}, e^{c-F}\right) & =W_{i}\left(e^{d-F}, e^{c-F}\right)-W_{i}\left(e^{c-F}, e^{c-F}\right) \\
& =\frac{\left(e^{d-F}-e^{c-F}\right)^{2}\left[\frac{\gamma\left(12 \gamma^{3}+36 \gamma^{2}+31 \gamma+9\right)}{(1+2 \gamma)^{2}(2 \gamma+3)^{2}}+1\right]}{2}>0
\end{aligned}
$$

and

$$
\begin{aligned}
C_{i}\left(e^{\phi-F}, e^{c-F}\right) & =W_{i}\left(e^{c-F}\right)-W_{i}\left(e^{\phi-F}\right) \\
& =\left[\frac{\Delta e^{F}}{2}\right]^{2}\left[\frac{\gamma(4 \gamma+9)}{(2 \gamma+3)^{2}}+8\right] \geq 0
\end{aligned}
$$

The critical discount factor $\bar{\delta}^{F}$ corresponds to the solution of $B_{i}\left(e^{d-F}, e^{c-F}\right)=\frac{\delta}{1-\delta} C_{i}\left(e^{\phi-F}, e^{c-F}\right)$ :

$$
\bar{\delta}^{F}=\frac{1}{2+\frac{\gamma(1+\gamma)\left(9+3 \gamma-4 \gamma^{2}\right)(3+2 \gamma)^{2}}{\left[24 \gamma^{3}+76 \gamma^{2}+69 \gamma+18\right]^{2}}} .
$$

Lemma 2: An IEA is self-sustainable under free trade if and only if $\delta \geq \bar{\delta}^{F}$ holds.

We now address our main question: is an IEA easier or harder to self-sustain under free trade?

Proposition 2: The range of discount factors over which an IEA is self-sustainable is smaller under free trade relative to autarky: $\bar{\delta}^{F}>\bar{\delta}^{A}$.

\section{Insert Figure 1}

In order to understand the above result, we examine the behavior of one period benefit and cost of defection under each regime. We have already argued in the previous section that oneperiod cost of defection (i.e. welfare gain from an IEA) is larger under free trade than under autarky: $C_{i}\left(e^{\phi-F}, e^{c-F}\right)>C_{i}\left(e^{\phi-A}, e^{c-A}\right)$. The same statement obtains for the one-period benefit from defection: $B_{i}\left(e^{d-F}, e^{c-F}\right)>B_{i}\left(e^{d-A}, e^{c-A}\right)$. However, once we consider the benefit cost ratios under these regimes, we obtain $\frac{B_{i}\left(e^{d-F}, e^{c-F}\right)}{C_{i}\left(e^{\phi-F}, e^{c-F}\right)}>\frac{B_{i}\left(e^{d-A}, e^{c-A}\right)}{C_{i}\left(e^{\phi-A}, e^{c-A}\right)}$ which implies that $\bar{\delta}^{F}>\bar{\delta}^{A}$. Intuitively, recall that the profit shifting effect does not exist under autarky but arises under free trade and this leads to a higher benefit-cost ratio under free trade relative to autarky.

The above proposition along with figure 1 argues in favor of the idea that, while free trade raises both the environmental and welfare gains from an IEA relative to autarky, it makes an IEA less likely to be self-sustainable. Let $\widehat{\delta}$ denote the actual (given) discount factor, we can distinguish three scenarios: (i) if $\widehat{\delta}>\max \left\{\bar{\delta}^{A}, \bar{\delta}^{F}\right\}$, an IEA is self-sustainable under both regimes (autarky and free trade), (ii) if $\bar{\delta}^{F}>\widehat{\delta}>\bar{\delta}^{A}$, an IEA is self-sustainable under autarky but not under free trade and (iii) if $\widehat{\delta}<\min \left\{\bar{\delta}^{A}, \bar{\delta}^{F}\right\}$, an IEA is not self-sustainable under either regime. It is also worth noting that $\bar{\delta}^{F}-\bar{\delta}^{A}$ rises as $\gamma$ increases. As a result, scenario (ii) is more likely to arise when the degree of the abatement cost's convexity gets larger.

Since an IEA is sustainable under autarky but not under free trade when $\bar{\delta}^{F}>\widehat{\delta}>\bar{\delta}^{A}$ holds, free trade bears an additional cost relative to autarky and it must be factored in when accounting for the net benefit of opening up to free trade. 


\section{Welfare Implications of Free Trade versus Autarky}

Before proceeding with the welfare implications of the above three scenarios, we first identify two effects that play important roles in the comparison of a country's welfare under free trade and autarky: the pure trade effect, denoted by $\Delta W_{i}^{P T}$, and the environmental damage effect, denoted by $\Delta W_{i}^{E D}$. The former effect represents the direct effect of opening up to trade isolated from the indirect environmental damage effect. To obtain the pure trade effect, we assume that opening up to free trade has no impact on the environmental policy and the emission standards are symmetric and equal to $e^{r-A}$ under both autarky and free trade, where $r=\phi, c$. Then, the pure trade effect is given by:

$$
\Delta W_{i}^{P T}\left(e^{r-A}\right)=W_{i}^{F}\left(e^{r-A}, e^{r-A}\right)-W_{i}^{A}\left(e^{r-A}, e^{r-A}\right)=\frac{(5+3 \gamma)\left(\alpha+\gamma e^{r-A}\right)^{2}}{2(3+2 \gamma)^{2}(2+\gamma)^{2}}>0, r=\phi, c
$$

It can be shown from (43) that $\frac{\partial \Delta W_{i}^{P T}\left(e^{r-A}, e^{r-A}\right)}{\partial \gamma}<0$ holds and thus positive pure trade effect falls as the rate of increase in the marginal cost of abatement $(\gamma)$ rises. In fact, under this situation an increase in $\gamma$ acts like an increase in the degree of convexity of the cost of production and lowers the potential benefits from free trade relative to autarky. We now examine the welfare implications of opening up to free trade for the three distinct scenarios above. This analysis sheds light on the nature of the environmental damage effect as well.

First consider scenario (i) where an IEA is self-sustainable under both regimes. While less stringent environmental standards arise under free trade relative to autarky $e^{c-A}<e^{c-F}$, countries always benefit from free trade relative to autarky:

$$
W_{i}\left(e^{c-F}, e^{c-F}\right)-W_{i}\left(e^{c-A}, e^{c-A}\right)=\frac{\alpha^{2}(5+3 \gamma)(4+\gamma)^{2}}{2\left[4(2 \gamma+3)^{2}+\gamma(4 \gamma+9)\right]\left[4(2+\gamma)^{2}+\gamma(\gamma+4)\right]}>0
$$

The above result along with (29) provides support for the idea that the benefit from opening up to trade comes at the expense of the environment even when environmental agreement is in place under free trade. Note from (44) that the environmental damage effect is dominated by the pure trade effect in this scenario for all $\gamma$ values. In fact, the pure trade effect and the environmental damage effect can be isolated as follows:

$$
\Delta W_{i}^{P T}\left(e^{c-A}\right)=W_{i}^{F}\left(e^{c-A}, e^{c-A}\right)-W_{i}^{A}\left(e^{c-A}, e^{c-A}\right)=\frac{\alpha^{2}(5+3 \gamma)(4+\gamma)^{2}(2 \gamma+3)^{2}}{2\left[4(2 \gamma+3)^{2}+\gamma(4 \gamma+9)\right]^{2}(2+\gamma)^{2}}>0
$$

and

$$
\begin{aligned}
\Delta W_{i}^{E D}\left(e^{c-A}, e^{c-F}\right) & =\left|W_{i}\left(e^{c-F}, e^{c-F}\right)-W_{i}\left(e^{c-A}, e^{c-A}\right)-\Delta W_{i}^{P T}\left(e^{c-A}, e^{c-A}\right)\right| \\
& =\frac{\alpha^{2} \gamma^{2}(5+3 \gamma)^{2}(4+\gamma)^{2}}{2\left[4(2 \gamma+3)^{2}+\gamma(4 \gamma+9)\right]^{2}\left[4(2+\gamma)^{2}+\gamma(\gamma+4)\right](2+\gamma)^{2}}
\end{aligned}
$$

Similar analysis applies to the other two scenarios. Now consider scenario (ii) where an IEA is self-sustainable under autarky but not under free trade. Once we compare the welfare level 
under autarky with an IEA $\left(W_{i}\left(e^{c-A}, e^{c-A}\right)\right)$ with the one under free trade with no environmental cooperation $\left(W_{i}\left(e^{\phi-F}, e^{\phi-F}\right)\right)$, we find that countries gain from free trade relative to autarky when the degree of abatement cost's convexity is sufficiently small (see figure 2):

$$
W_{i}\left(e^{\phi-F}, e^{\phi-F}\right)-W_{i}\left(e^{c-A}, e^{c-A}\right) \geq 0 \text { iff } \gamma \geq \underline{\gamma} \cong 1.01
$$

Insert Figure 2

The intuition behind the above result can be understood as follows. Under this scenario, the pure trade effect stays the same as in (45) under scenario (i) while the environmental damage effect widens up since $e^{c-F}<e^{\phi-F}: \Delta W_{i}^{E D}\left(e^{c-A}, e^{\phi-F}\right)>\Delta W_{i}^{E D}\left(e^{c-A}, e^{c-F}\right)$. Moreover, as noted before, as $\gamma$ increases, the trade effect becomes less important and thus the damage effect outweighs the trade effect when $\gamma$ is sufficiently large.

Finally, consider scenario (iii) where an IEA is not self-sustainable under both autarky and free trade. The pure trade effect and environmental damage effects can be found as follows:

$\Delta W_{i}^{P T}\left(e^{\phi-A}\right)=W_{i}^{F}\left(e^{\phi-A}, e^{\phi-A}\right)-W_{i}^{A}\left(e^{\phi-A}, e^{\phi-A}\right)=\frac{\alpha^{2}(5+3 \gamma)(1+2 \gamma)^{2}(2 \gamma+3)^{2}}{\left[\gamma\left[9(\gamma+1)^{2}-\gamma^{2}+2 \gamma\right]+2(1+2 \gamma)(2 \gamma+3)\right]^{2}}>0$

and

$$
\begin{aligned}
\Delta W_{i}^{E D}\left(e^{\phi-A}, e^{\phi-F}\right) & =\left|W_{i}\left(e^{\phi-F}, e^{\phi-F}\right)-W_{i}\left(e^{\phi-A}, e^{\phi-A}\right)-\Delta W_{i}^{P T}\left(e^{\phi-A}, e^{\phi-A}\right)\right| \\
& =\frac{\alpha^{2} \gamma^{2}(13+8 \gamma)(1+\gamma)\left(96 \gamma^{5}+824 \gamma^{4}+2637 \gamma^{3}+3889 \gamma^{2}+2612 \gamma+640\right)}{2\left[\gamma\left[9(\gamma+1)^{2}-\gamma^{2}+2 \gamma\right]+2(1+2 \gamma)(2 \gamma+3)\right]^{2}\left[2(2+\gamma)^{2}+\gamma(\gamma+4)\right]^{2}}
\end{aligned}
$$

Similar to scenario (ii), when the rate of increase in marginal cost of abatement is sufficiently large, we show that the environmental damage effect outweighs the pure trade effect and countries lose from free trade relative to autarky (see figure 3):

$$
W_{i}\left(e^{\phi-F}, e^{\phi-F}\right)-W_{i}\left(e^{\phi-A}, e^{\phi-A}\right) \geq 0 \text { iff } \gamma \geq \bar{\gamma} \cong 3.17
$$

Insert Figure 3

We have established the following result:

Proposition 3: We have (i) when $\gamma<\underline{\gamma}$, free trade yields a larger welfare relative than autarky for all $\widehat{\delta}$; (ii) when $\underline{\gamma}<\gamma<\bar{\gamma}$, welfare under autarky is larger than under free trade if and only if $\bar{\delta}^{F}>\widehat{\delta}>\bar{\delta}^{A}$ holds; (iii) when $\gamma>\bar{\gamma}$, welfare under autarky is larger than under free trade if and only if $\widehat{\delta}<\bar{\delta}^{F}$ holds.

It is important to note that whenever free trade dominates autarky from a social welfare perspective, the gain comes at the expense of the environmental quality. When $\gamma$ is sufficiently large and the actual discount factor is sufficiently small, autarky not only yields higher social welfare but also better environmental quality relative to free trade. 
So far, we have followed the existing literature and focused on the two polar cases where either countries can implement the cooperative outcome or they fail and the non-cooperative outcome prevails. ${ }^{6}$ In reality given a discount factor, even though implementing the fully cooperative outcome is not sustainable, countries may opt for an agreement with an 'intermediate' level of cooperation that is sustainable. ${ }^{7}$

\section{Most Cooperative Environmental Policy}

In this section, we consider the possibility where countries can sign an IEA with the most cooperative environmental policy when an 'optimally designed' IEA is not sustainable under a trade regime. Given a level of the discount factor, we find the lowest symmetric emission standards (denoted by $\underline{e}^{c-F}$ and $\underline{e}^{c-A}$ ) for which cooperation is acceptable to both countries and the incentive compatibility constraint in (36) just binds: $B_{i}\left(\underline{e}^{d-Z}, \underline{e}^{c-Z}\right)=\frac{\delta}{1-\delta} C_{i}\left(e^{\phi-Z}, \underline{e}^{c-Z}\right)$.

\subsection{Autarky}

When an 'optimally designed IEA' is not self-sustainable under autarky $\left(\widehat{\delta}<\bar{\delta}^{A}\right)$, countries can agree on a cooperative emission standard $\underline{e}^{c-A}$ that is higher than optimum cooperative standard $e^{c-A}$ and lower than optimum non-cooperative standard $e^{\phi-A}$. Then, country $i$ 's defection problem becomes:

$$
\max _{e_{i}} W_{i}\left(e_{i}, \underline{e}^{c-A}\right)=C S_{i}\left(e_{i}, \underline{e}^{c-A}\right)+P S_{i}\left(e_{i}, \underline{e}^{c-A}\right)-\Omega_{i}\left(e_{i}, \underline{e}^{c-A}\right)
$$

The solution to the above problem yields the optimum defection standards, denoted by $\underline{e}^{d-A}$ :

$$
\underline{e}^{d-A}=\frac{\alpha \gamma(3+\gamma)-(2+\gamma)^{2} \underline{e}^{c-A}}{2\left(\gamma^{2}+4 \gamma+2\right)}
$$

It is straightforward to find the per period cost and benefit from defection:

$$
B_{i}\left(\underline{e}^{d-A}, \underline{e}^{c-A}\right)=\frac{\left(\gamma^{2}+4 \gamma+2\right)}{(2+\gamma)^{2}}\left[\frac{\alpha \gamma(3+\gamma)-\left(3 \gamma^{2}+12 \gamma+8\right) \underline{e}^{c-A}}{2\left(\gamma^{2}+4 \gamma+2\right)}\right]^{2}
$$

and

$$
C_{i}\left(e^{\phi-A}, \underline{e}^{c-A}\right)=\frac{\alpha^{2}(3+\gamma)+2 \alpha \gamma(3+\gamma) \underline{e}^{c-A}-\left(5 \gamma^{2}+20 \gamma+16\right)\left[\underline{e}^{c-A}\right]^{2}}{2(2+\gamma)^{2}}-\frac{\alpha^{2}(3+\gamma)\left[\gamma^{2}(\gamma-4)+16(1+\gamma)^{2}\right]}{2\left[2(2+\gamma)^{2}+\gamma(\gamma+4)\right]^{2}}
$$

We find $\underline{e}^{c-A}$ that solves $B_{i}\left(\underline{e}^{d-A}, \underline{e}^{c-A}\right)=\frac{\delta}{1-\delta} C_{i}\left(e^{\phi-A}, \underline{e}^{c-A}\right)$ :

$$
\underline{e}^{c-A}=\frac{8 \alpha(3+\gamma)\left(\gamma^{2}+4 \gamma+2\right)\left(3 \gamma^{2}+12 \gamma+8\right)}{(4+\gamma)\left[\delta \gamma(4+\gamma)(2+\gamma)^{2}+\left(3 \gamma^{2}+12 \gamma+8\right)^{2}\right]}-\frac{\alpha(3+\gamma)\left(7 \gamma^{2}+28 \gamma+16\right)}{(4+\gamma)\left(3 \gamma^{2}+12 \gamma+8\right)}
$$

\footnotetext{
${ }_{7}^{6}$ See Carraro and Siniscalco (1993), Barrett (1994a), and Finus (2001).

${ }^{7}$ This approach is very similar to the one used in the trade agreement literature such as Chisik (2003) and Saggi (2006). They find the most cooperative tariff levels in a dynamic tariff war game.
} 
It is immediate from (53) that as countries become more patient, they are willing to cooperate on a lower (stricter) emission standard: $\frac{\partial e^{c-A}}{\partial \delta}<0$. Note also that as the discount factor converges to zero, any kind of environmental cooperation becomes unsustainable and thus $\underline{e}^{c-A}$ approaches to $e^{\phi-A}$ :

$$
\lim _{\delta \rightarrow 0}\left(\underline{e}^{c-A}\right)=e^{\phi-A}
$$

When $\widehat{\delta}<\bar{\delta}^{A}$ holds, we find the welfare of a country under autarky with a cooperative standard $\underline{e}^{c-A}$ as follows:

$$
W\left(\underline{e}^{c-A}\right)=\frac{\alpha^{2}(3+\gamma)+2 \alpha \gamma(3+\gamma) \underline{e}^{c-A}-\left(5 \gamma^{2}+20 \gamma+16\right)\left[\underline{e}^{c-A}\right]^{2}}{2(2+\gamma)^{2}}
$$

We examine below the same possibility under free trade.

\subsection{Free Trade}

Suppose that $\widehat{\delta}<\bar{\delta}^{F}$ holds and an 'optimally designed' IEA is not self-sustainable under free trade. In such a case, countries can opt for a cooperative emission standard $\underline{e}^{c-F}$ (higher than $e^{c-F}$ but lower than $\left.e^{\phi-F}\right)$. Similar to the case of autarky, country $i$ 's defection problem is given by:

$$
\max _{e_{i}} W_{i}\left(e_{i}, \underline{e}^{c-F}\right)=C S_{i}\left(e_{i}, \underline{e}^{c-F}\right)+P S_{i}\left(e_{i}, \underline{e}^{c-F}\right)-\Omega_{i}\left(e_{i}, \underline{e}^{c-F}\right)
$$

The solution to the above problem yields $\underline{e}^{d-F}$ as a function of $\underline{e}^{c-F}$ :

$$
\underline{e}^{d-F}=\frac{\zeta_{1}-\underline{e}^{c-F} \zeta_{2}}{\zeta_{3}}
$$

where

$$
\begin{aligned}
& \zeta_{1}=2 \alpha \gamma(2 \gamma+1)\left(4 \gamma^{2}+10 \gamma+5\right) \\
& \zeta_{2}=(\gamma+1)\left(20 \gamma^{3}+56 \gamma^{2}+39 \gamma+9\right) \\
& \zeta_{3}=28 \gamma^{4}+100 \gamma^{3}+119 \gamma^{2}+57 \gamma+9
\end{aligned}
$$

Given these standards $\underline{e}^{d-F}$ and $\underline{e}^{c-F}$, the per period cost and benefit from defection are as follows:

$$
B_{i}\left(\underline{e}^{d-F}, \underline{e}^{c-F}\right)=\frac{\zeta_{3}}{2 \alpha \gamma}\left[\frac{\frac{\zeta_{1}-\underline{e}^{c-F}\left(\zeta_{2}+\zeta_{3}\right)}{\zeta_{3}}}{(2 \gamma+1)(2 \gamma+3)}\right]^{2}
$$

and

$$
C_{i}\left(e^{\phi-F}, \underline{e}^{c-F}\right)=\frac{\left[4(2 \gamma+3)^{2}+\gamma(4 \gamma+9)\right]\left[\underline{e}^{c-F}\right]^{2}+8 \alpha \gamma(2+\gamma) \underline{e}^{c-F}+4 \alpha^{2}(2+\gamma)}{2(2 \gamma+3)^{2}}-W\left(e^{\phi-F}\right) .
$$

It is immediate to find $\underline{e}^{c-F}$ that solves $B_{i}\left(e^{d-F}\left(\underline{e}^{c-F}\right), \underline{e}^{c-F}\right)=\frac{\delta}{1-\delta} C_{i}\left(e^{\phi-F}, \underline{e}^{c-F}\right)$ : 


$$
\underline{e}^{c-F}=\frac{4 \alpha \gamma\left(8 \gamma^{2}+21 \gamma+12\right) \zeta_{3} \zeta_{4}}{\zeta_{5}\left[\gamma(3+2 \gamma)^{2} \zeta_{5} \delta-\zeta_{4}^{2}\right]}+\frac{2 \alpha \zeta_{6}}{\zeta_{4} \zeta_{5}}
$$

where

$$
\begin{aligned}
& \zeta_{4}=\gamma\left[9(\gamma+1)^{2}-\gamma^{2}+2 \gamma\right]+2(1+2 \gamma)(2 \gamma+3)^{2} \\
& \zeta_{5}=(1+\gamma)\left(4 \gamma^{2}-3 \gamma-9\right) \\
& \zeta_{6}=464 \gamma^{6}+2820 \gamma 5+6758 \gamma^{4}+8159 \gamma^{3}+5244 \gamma^{2}+1701 \gamma+216
\end{aligned}
$$

Similar to the autarkic case, we obtain the following results under free trade: (i) as countries become more patient, they are willing to cooperate on a lower (more stringent) emission standard under free trade: $\frac{\partial e^{c-F}}{\partial \delta}<0$; (ii) as the discount factor converges to zero, $\underline{e}^{c-F}$ approaches to $e^{\phi-F}$ :

$$
\lim _{\delta \rightarrow 0}\left(\underline{e}^{c-F}\right)=e^{\phi-F}
$$

Note that the above analysis implies that, when $\widehat{\delta}<\bar{\delta}^{F}$ holds, the following welfare level obtains under free trade with a cooperative standard $\underline{e}^{c-F}$ (as stated above):

$$
W\left(\underline{e}^{c-F}\right)=\frac{\left[4(2 \gamma+3)^{2}+\gamma(4 \gamma+9)\right]\left[\underline{e}^{c-F}\right]^{2}+8 \alpha \gamma(2+\gamma) \underline{e}^{c-F}+4 \alpha^{2}(2+\gamma)}{2(2 \gamma+3)^{2}} .
$$

By comparing the emission standards and welfare under autarky and free trade, we can now state the following result:

Proposition 4: Suppose that $\widehat{\delta}<\bar{\delta}^{F}$ holds, we have: (i) $\underline{e}^{c-F}>\underline{e}^{c-A}$ for all $\gamma>0$ and $\widehat{\delta}>0$; (ii) when $\gamma<\bar{\gamma}$, free trade yields a larger welfare than autarky for all $\widehat{\delta}$; (iii) when $\gamma>\bar{\gamma}$ holds, there exists a threshold $\widetilde{\delta}<\bar{\delta}^{F}$ such that welfare under autarky is larger than under free trade if and only if $\widehat{\delta}<\widetilde{\delta}$ where $\frac{\partial \widetilde{\delta}}{\partial \gamma}>0$.

The first part of the above proposition argues that, irrespective of whether a self-sustainable IEA is optimally designed or not, free trade leads to higher emission standards worsening the environmental quality. This result provides a confirmation to our previous result that any welfare gain from free trade always comes at the expense of the environmental quality. Then, we consider the following question: would the higher environmental damage under free trade be enough for autarky to dominate free trade from a social welfare perspective? The second part of the above proposition provides a negative answer to this question when the rate of increase in marginal cost of abatement is sufficiently low $(\gamma<\bar{\gamma})$. Under such a case, pure trade effect dominates the indirect environmental damage effect. On the other hand, autarky yields a higher welfare than under free trade when (i) the rate of increase in the marginal cost of abatement is sufficiently high $(\gamma>\bar{\gamma})$ and (ii) countries are sufficiently impatient $(\widehat{\delta}<\widetilde{\delta})$. 


\section{Concluding remarks}

This paper contributes to the large literature devoted to the welfare implications of free trade when economic activities generate pollution which causes a transboundary damage. Our main contribution is to incorporate the impact of free trade on the sustainability of environmental agreements into the assessment of the net benefits of opening up to free trade. We have demonstrated that

this impact of free trade can be significant and reverse the conclusions reached in the analysis of a standard one-shot game. More specifically, while in the one shot game version of our international pollution trade game, the benefits from the increase in economic activity due to free trade outweigh the extra cost of free trade associated with larger environmental damage, in the case of a repeated game, free trade can prevent the sustainability of an IEA that would be sustainable under autarky. This aggravates the environmental damages caused by free trade and leads to the possibility that autarky may welfare-dominate free trade.

Reaching an international environmental agreement is clearly a difficult and often an elusive objective. It can be safely stated that most IEAs are the outcome of difficult negotiations and correspond to a compromise of involving parties. In other words, countries ultimately agree on the most cooperative environmental policy rather than implementing the fully cooperative environmental policy. Based upon this observation, we consider the possibility where countries can sign an IEA with the most cooperative environmental policy when an 'optimally designed' IEA is not sustainable. Our analysis provides a confirmation to the main result derived under the polar cases of cooperative and non-cooperative environmental policies: there are cases where autarky dominates free trade from a social welfare perspective.

\section{References}

[1] Bagwell, K., and R. W. Staiger (1997a), "Multilateral Tariff Cooperation during the Formation of Free Trade Areas", International Economic Review, 38, 291-319 .

[2] Bagwell, K., and R. W. Staiger (1997b), "Multilateral Tariff Cooperation during the Formation of Customs Unions", Journal of International Economics, 42, 91-123.

[3] Bagwell, K., and R. W. Staiger (1998), "Will Preferential Agreements undermine the Multilateral Trading System?", Economic Journal, 108, 1162-1182.

[4] Baksi, Soham, and Amrita Ray Chaudhuri (2008) "Transboundary Pollution, Trade Liberalization, and Environmental Taxes", CentER Discussion Paper, 2008-78, Tilburg University.

[5] Barrett, Scott (1994a). "Self-Enforcing International Environmental Agreements," Oxford Economic Papers, 46, 878-894.

[6] Barrett, Scott (1994b), Strategic Environmental Policy and International Trade, Journal of Public Economics, 54, 325-338. 
[7] Bhagwati, Jagdish (1993). "The Case for Free Trade," Scientific American, 42-49 (1993)

[8] Bond, E. W., C. Syropoulos, and L. A. Winters (2001), "Deepening of Regional Integration and Multilateral Trade Agreements", Journal of International Economics, 53, 335-362.

[9] Burguet, Robert, and Jaume Sempere (2003). "Trade Liberalization, Environmental Policy, and Welfare," Journal of Environmental Economics and Management, 46, 25-37.

[10] Carraro, Carlo and Domenico Siniscalco (1993), Strategies for the international protection of the environment, Journal of Public Economics 52 309-328.

[11] Chisik, Richard (2003). "Gradualism in free trade agreements: a theoretical justification" Journal of International Economics, 59, 367-397.

[12] Copeland, B. R., and M. S. Taylor (1995), Trade and Transboundary Pollution, American Economic Review, 85, 716-737.

[13] Dua, Andre and Daniel C. Esty (1997). Sustaining the Asia Pacific Miracle: Environmental Protection and Economic Integration. Washington: Institute for International Economics.

[14] Ederington, Josh (2001). "International Coordination of Trade and Domestic Policies," American Economic Review, 91, 1580-1593.

[15] Ederington, Josh and Jenny Minier (2003). "Is environmental policy a secondary trade barrier? An empirical analysis," Canadian Journal of Economics, 36, 137-154.

[16] Ederington, Josh (2009). "Negotiating over Environmental Policy in Trade Agreements." University of Kentucky (mimeo).

[17] Ferrara, Ida, Paul Missios and Halis M. Yildiz (2009). "Trading Rules and the Environment: Does Equal Treatment Lead to a Cleaner World?," Journal of Environmental Economics and Management, forthcoming.

[18] Finus, Michael (2001) "Game theory and international environmental cooperation," Edward Elgar, Cheltenman, UK ; Northampton, MA.

[19] Kennedy, Peter W. (1994). "Equilibrium Pollution Taxes in Open Economies with Imperfect Competition," Journal of Environmental Economics and Management, 27, 49-63.

[20] Krugman, Paul (1997) "What should trade negotiators negotiate about?," Journal of Economic Literature 35, 113-20.

[21] Lawrence, Robert et al. (1996). A Vision for the World Economy. Washington: Brookings Institution. 
[22] Riezman, Raymond (1991), "Dynamic Tariffs with Asymmetric Information", Journal of International Economics, 30, 267-283.

[23] Rubio, Santiago J. and Alistair Ulph (2007), "An infinite-horizon model of dynamic membership of international environmental agreements," Journal of Environmental Economics and Management, 54, 296-310.

[24] Saggi, Kamal (2006), "Preferential Trading Agreements and Multilateral Tariff Cooperation", International Economic Review, 47, 29-57.

[25] Straume, Odd R. (2006). "Product Market Integration and Environmental Policy Coordination in an International Duopoly," Environmental and Resource Economics, 34, 535-563.

[26] Ulph, Alistair (1996a). "Environmental policy and international trade when governments and producers act strategically," Journal of Environmental Economics and Management, 30, 265281.

[27] Ulph, Alistair (1996b), Strategic Environmental Policy, International Trade and the Single European Market, in "Environmental Policy with Political and Economic Integration: The European Union and the United States" (J. Branden, H. Folmer, T. Ulen, Eds.) Edward Elgar Publishing Limited, London, UK. 


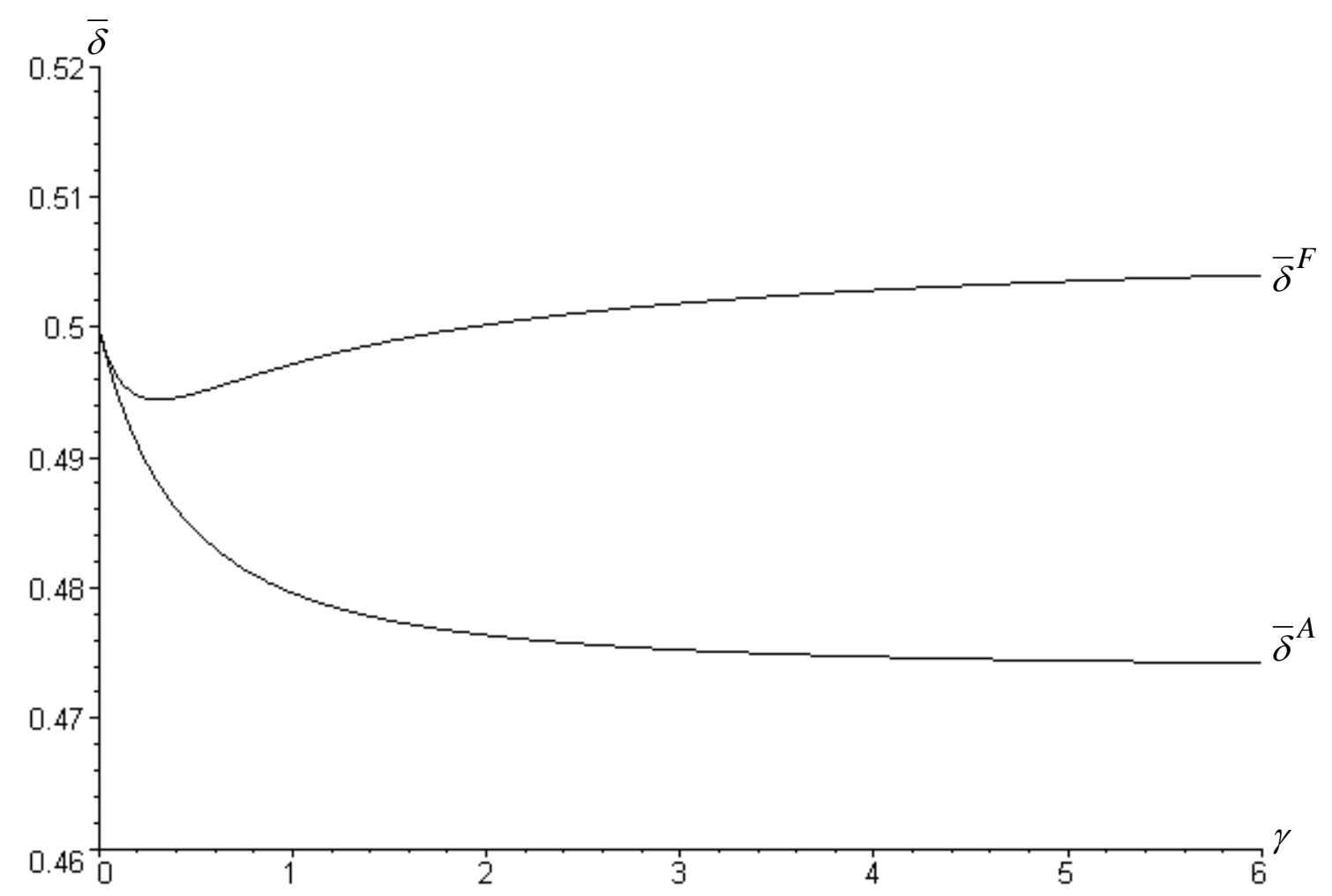

Figure 1: Sustainability of an IEA: Free Trade versus Autarky

$W_{i}\left(e^{\phi-F}\right)-W_{i}\left(e^{c-A}\right)$

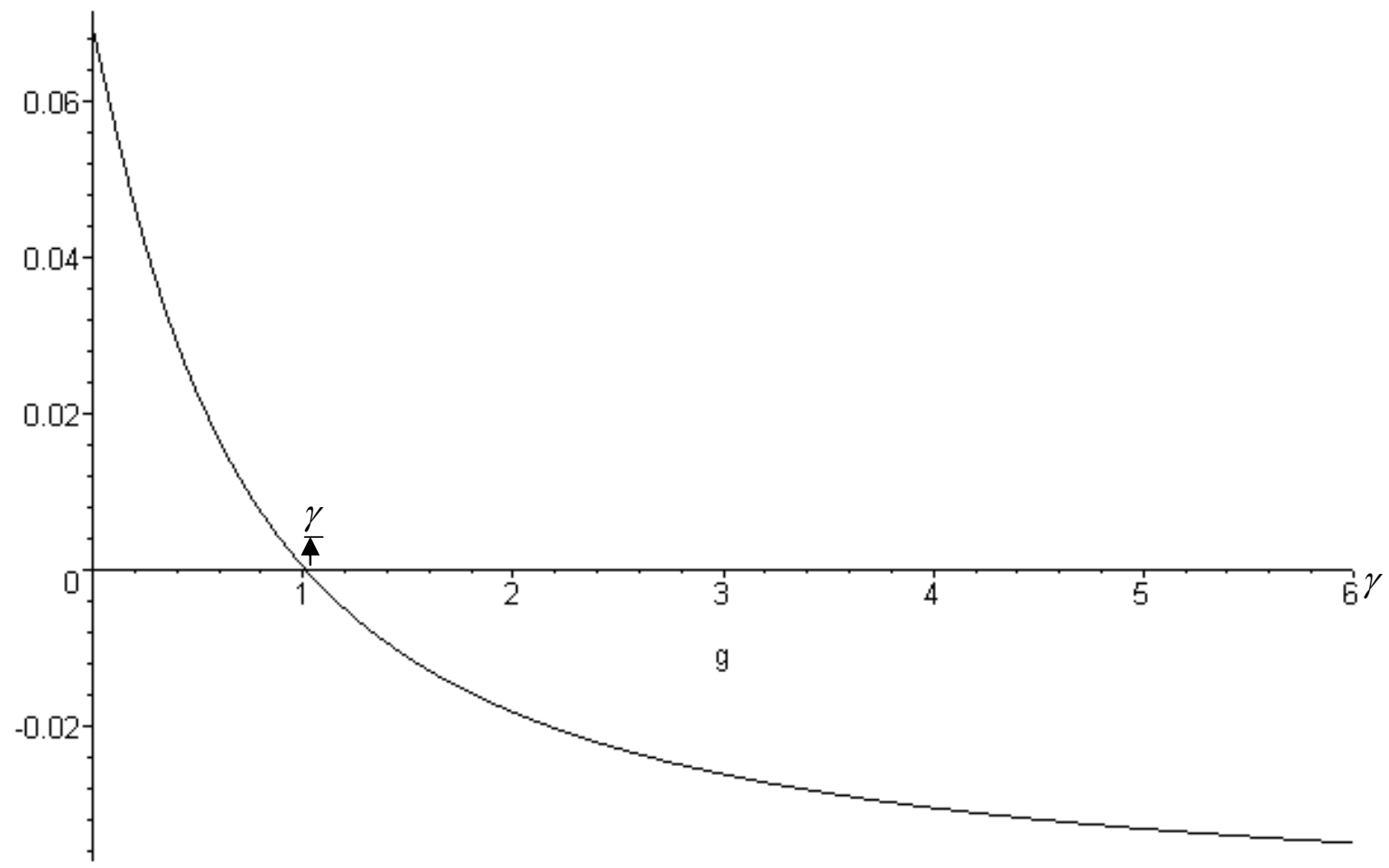

Figure 2: Welfare Comparison: IEA under Autarky but not under Free Trade 


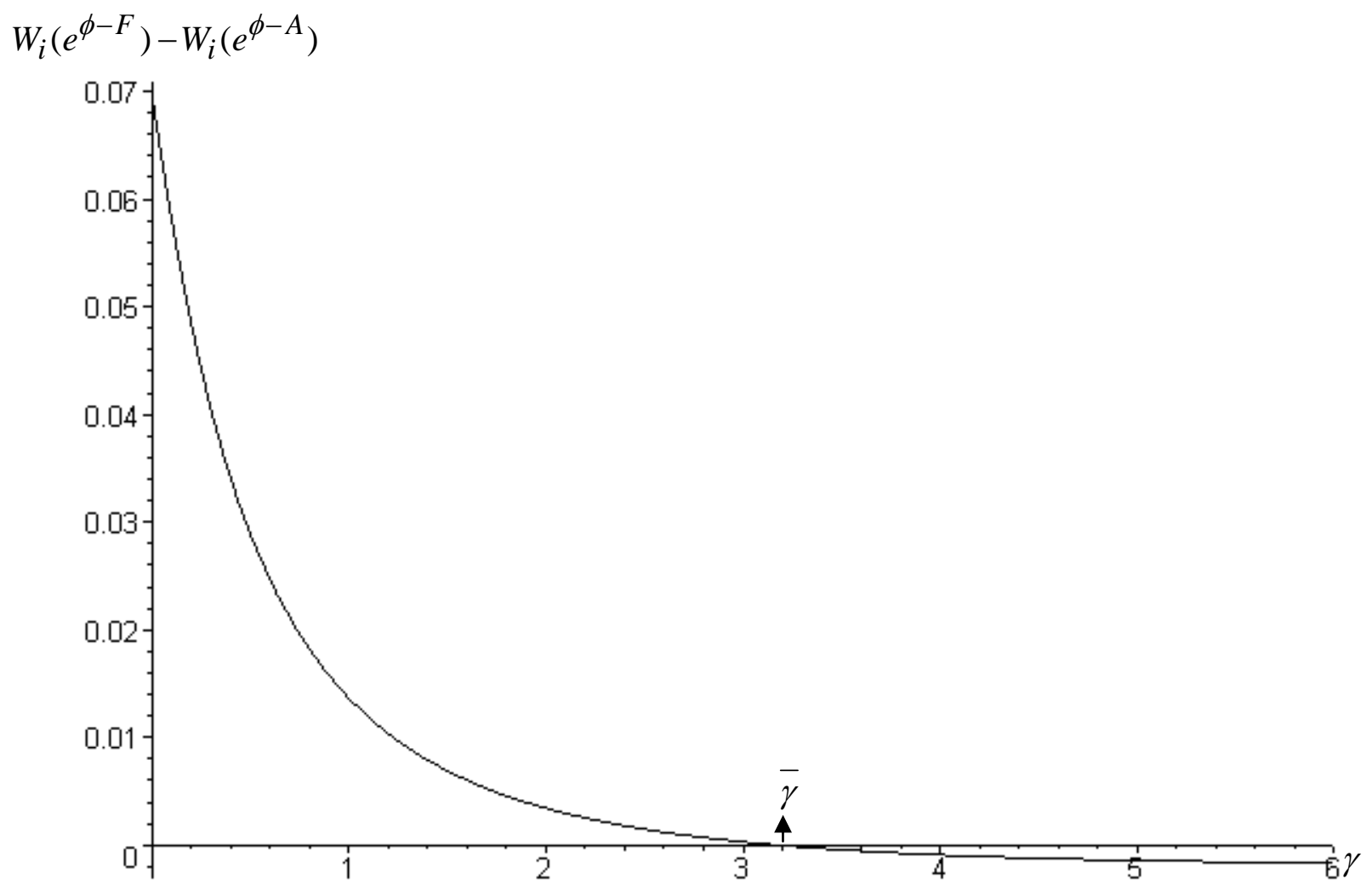

Figure 3: Welfare Comparison: No cooperation under Autarky and Free Trade 